\title{
Technical Basis for Extended Dry Storage of Aluminum- Clad Spent Nuclear Fuel
}

\section{December 2021}

Technical Report

Elmar Eidelpes and Josh Jarrell

Idaho National Laboratory

Robert Sindelar

Savannah River National Laboratory

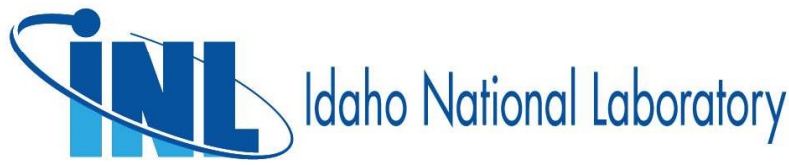




\section{DISCLAIMER}

This information was prepared as an account of work sponsored by an agency of the U.S. Government. Neither the U.S. Government nor any agency thereof, nor any of their employees, makes any warranty, expressed or implied, or assumes any legal liability or responsibility for the accuracy, completeness, or usefulness, of any information, apparatus, product, or process disclosed, or represents that its use would not infringe privately owned rights. References herein to any specific commercial product, process, or service by trade name, trademark, manufacturer, or otherwise, does not necessarily constitute or imply its endorsement, recommendation, or favoring by the U.S. Government or any agency thereof. The views and opinions of authors expressed herein do not necessarily state or reflect those of the U.S. Government or any agency thereof. 


\title{
Technical Basis for Extended Dry Storage of Aluminum-Clad Spent Nuclear Fuel
}

\author{
Technical Report
}

Elmar Eidelpes and Josh Jarrell

Idaho National Laboratory

Robert Sindelar

Savannah River National Laboratory

December 2021

Idaho National Laboratory

Idaho Falls, Idaho 83415

http://www.inl.gov

Prepared for the

U.S. Department of Energy

Office of Environmental Management

Under DOE Idaho Operations Office

Contract DE-AC07-05ID14517 
Page intentionally left blank 


\section{EXECUTIVE SUMMARY}

The Department of Energy owns a large inventory ( 14 MTHM or $\sim 19,000$ assemblies) of aluminum-clad spent nuclear fuel (ASNF) that is presently in interim storage, and continued, safe storage of ASNF must be provided over extended periods of time ( $>50$ years) pending ultimate disposition. To support active reactor operations and ensure safe ASNF management practices, several research activities were initiated to formulate the technical basis for extended dry storage. Within the scope of these activities, technical understanding was developed to answer whether ASNF can remain in its existing (vented) dry storage and whether it can be placed in a system for sealed dry storage for extended periods. That is, the research presented in this report completes existing subject matter literature listed in DOE-ID/RPT-1575 "Aluminum-Clad Spent Nuclear Fuel: Technical Considerations and Challenges for Extended ( $>50$ Years) Dry Storage." The activities were conducted under the sponsorship of the Department of Energy, Office of Environmental Management-Technology Development (EMTD).

The primary questions involving extended dry storage of ASNF center around the adequacy of pre-storage drying processes and the behavior of residual hydrated oxides, or (oxy)hydroxides corrosion layers - specifically, the radiolytic breakdown of adsorbed and chemically bound water in these corrosion products. This radiation-induced decomposition yields chemical species such as molecular hydrogen gas $\left(\mathrm{H}_{2}\right)$. Thus, the development of a dataset describing ASNF condition-specific radiolytic $\mathrm{H}_{2}$ yields and formation rates as well as the modeling and simulation (M\&S) of the performance of ASNF in sealed and vented dry storage canisters are important activities within the scope of the EMTD project.

This report addresses previously identified technical knowledge and technology gaps and presents the key findings of the multiyear, EMTD-funded research efforts with the goal of evaluating whether ASNF can be safely stored dry for many decades and whether changes to existing ASNF management practices are appropriate. The findings formulate the technical basis for the extended dry storage of ASNF, leading to the main conclusion:

All completed work to close the identified knowledge gaps on extended (>50 years) ASNF dry storage supports the conclusion that extended ASNF dry storage is both safe and viable. 
More specifically, the following conclusions can be drawn pertaining to the safety and viability of (1) extended, vented dry storage, (2) extended, sealed dry storage, and (3) technological approaches to monitor vented and sealed ASNF dry storage configurations:

1. Extended, vented dry storage of ASNF is both safe and viable. The radiolytic gas generation testing, characterization of actual ASNF sampled from wet and dry storage, drying technology evaluations, as well as the M\&S of the ASNF performance in its current dry storage configurations show that ASNF presently contained in vented dry storage canisters can remain safely stored for extended dry storage periods in their current configurations pending ultimate disposition. That is, the yield of chemical species, such as nitric acid, $\mathrm{H}_{2}$, and oxygen $\left(\mathrm{O}_{2}\right)$, do not raise any canister corrosion or flammability concerns.

2. Extended, sealed dry storage of ASNF is both safe and viable. The radiolytic gas generation testing, characterization of actual ASNF sampled from wet and dry storage, drying technology evaluations, as well as the M\&S of ASNF performance in potential future dry storage configurations show that ASNF can be safely placed in sealed dry storage canister for extended periods of time without causing corrosion degradation, canister pressurization, or canister flammability challenges, pending ultimate disposition. That is, the yield of chemical species, such as nitric acid, $\mathrm{H}_{2}$, and $\mathrm{O}_{2}$, do not raise any canister corrosion, overpressurization, or flammability concerns.

3. Monitoring of extended dry storage of ASNF is technically viable. Reliable technology to monitor the performance of ASNF in vented and sealed dry storage systems was identified and prototypic instrumentation systems were developed. These systems could be utilized to further validate and verify the key findings of the conducted evaluations, providing additional assurance of safe and effective ASNF dry storage until final disposition. 
Page intentionally left blank 


\section{CONTENTS}

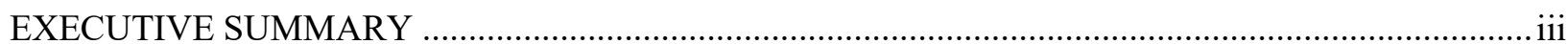

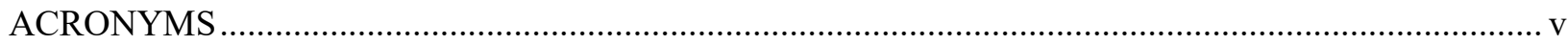

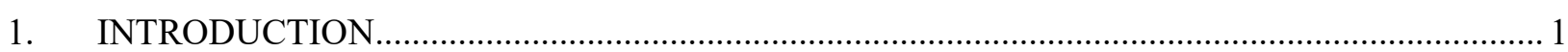

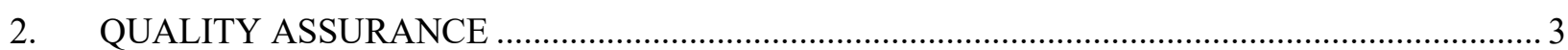

3. TECHNICAL BASIS FOR EXTENDED DRY STORAGE OF ASNF ........................................ 3

3.1 Behavior and Chemistry of (Oxy)hydroxide Layers for the Range of ASNF Designs

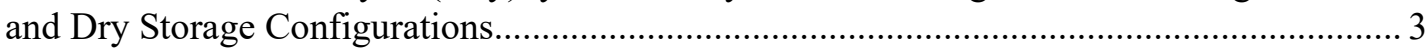

3.2 Resolution of Radiolytic Gas Generation Data for ASNF (Oxy)hydroxide Layers................ 4

3.3 Combined Effect of Episodic Breathing and Radiolytic Generation of Potentially Corrosive Gases in Sealed and Vented Systems. ........................................................................ 5

3.4 Performance of Research Test Reactor ASNF in Existing Dry Storage Systems.................. 6

3.5 Effects of High-Temperature (i.e., Greater than $100^{\circ} \mathrm{C}$ ) Drying on the Chemistry and Behavior of (Oxy)hydroxide Layers. ............................................................................... 7

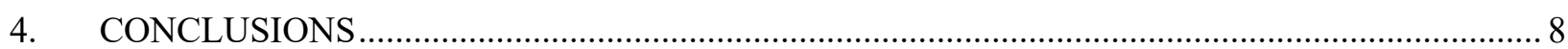

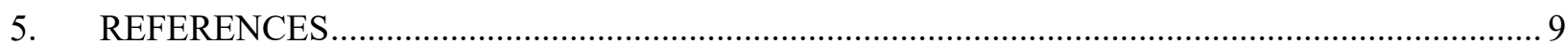

\section{FIGURES}

Figure 1. Pathway to ensure technology readiness for the extended dry storage of ASNF. . .1 
Page intentionally left blank 


\section{ACRONYMS}

ASNF aluminum-clad spent nuclear fuel

ATR Advanced Test Reactor

DOE Department of Energy

EMTD Department of Energy, Office of Environmental Management-Technology Development

FHD forced helium dehydration

INL Idaho National Laboratory

MURR University of Missouri Research Reactor

M\&S modeling and simulation

SNF spent nuclear fuel

SNFWG Spent Nuclear Fuel Working Group

SRNL Savannah River National Laboratory 
Page intentionally left blank 


\section{Technical Basis for Extended Dry Storage of Aluminum-Clad Spent Nuclear Fuel}

\section{INTRODUCTION}

The Department of Energy (DOE) owns a large inventory ( 14 MTHM or $\sim 19,000$ assemblies) of aluminum-clad spent nuclear fuel (ASNF) that is presently in interim storage. ${ }^{1,2}$ Since the $1990 \mathrm{~s}$, part of this ASNF was placed in vented dry storage canisters, and previously completed technical analyses provide a safety basis for the dry storage of ASNF until 2035. ${ }^{2}$ To support continued reactor operations and ASNF management practices, additional research activities were completed, allowing for the formulation of a technical basis for extended ASNF dry storage periods of 50 years or more. ${ }^{3}$ These activities were conducted under the sponsorship of the DOE, Office of Environmental ManagementTechnology Development (EMTD). ${ }^{4,5}$ Figure 1 presents a pathway including four steps to ensure technology readiness for the extended dry storage of ASNF.

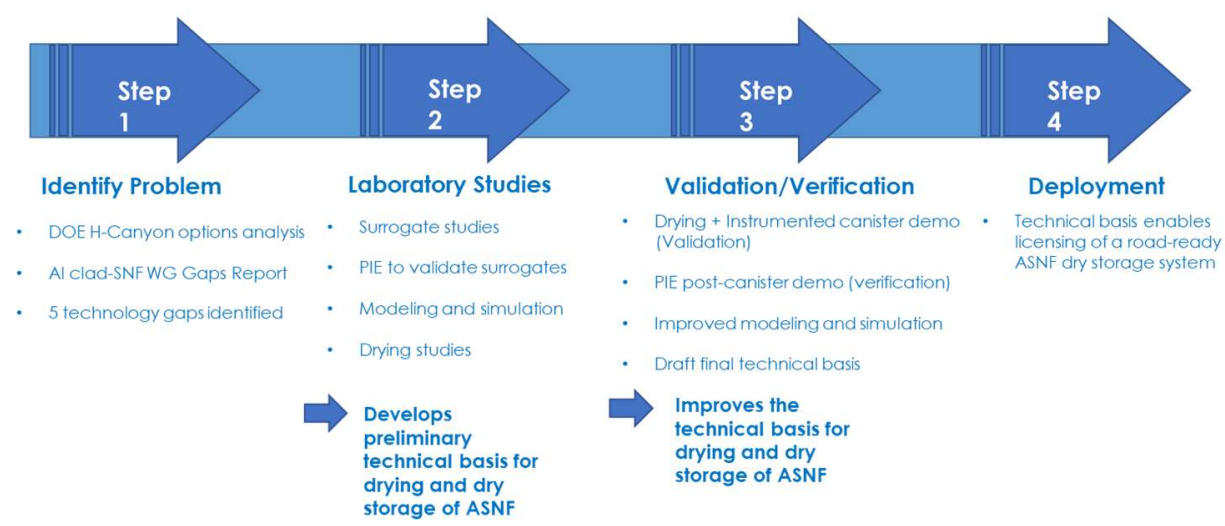

Figure 1. Pathway to ensure technology readiness for the extended dry storage of ASNF.

The DOE Spent Nuclear Fuel Working Group's (SNFWG's) perception of the technical basis needed to enable the safe, extended dry storage of ASNF is extensively described in DOE-ID/RPT-1575 "Aluminum-Clad Spent Nuclear Fuel: Technical Considerations and Challenges for Extended ( $>50$ Years) Dry Storage." The report identified five gaps (Step 1) to be addressed to better inform decision makers as to the environmental, safety, and long-term risks associated with strategies for managing ASNF in extended dry storage: ${ }^{1}$

1. Behavior and chemistry of (oxy)hydroxide layers for the range of ASNF designs and dry storage configurations

2. Resolution of radiolytic gas generation data for ASNF (oxy)hydroxide layers

3. Combined effect of episodic breathing and radiolytic generation of potentially corrosive gases in sealed and vented systems

4. Performance of research test reactor ASNF in existing dry storage systems

5. Effects of high-temperature (i.e., greater than $100^{\circ} \mathrm{C}$ ) drying on the chemistry and behavior of (oxy)hydroxide layers.

The primary challenge involving extended dry storage of ASNF centers around the behavior of hydrated-oxide, or (oxy)hydroxides corrosion layers - specifically, the radiolytic breakdown of adsorbed and chemically bound water in these corrosion products. This breakdown yields chemical species such as 
hydrogen gas $\left(\mathrm{H}_{2}\right)$. The development of an adequate understanding of this behavior, as well as modeling of the performance of ASNF in sealed and vented dry storage canisters, was needed to provide sufficient confidence in the behavior of ASNF in dry storage over extended periods.

An action plan and project execution plans were created, and in October 2018, a task-based project was launched (Step 2) under the sponsorship of EMTD to close the identified gaps and obtain the technical information needed to implement the extended dry storage of ASNF. ${ }^{4,5,6}$ A team composed of spent nuclear fuel (SNF) management and subject matter experts from Idaho National Laboratory (INL) and Savannah River National Laboratory (SRNL) was assembled. Technical leads for each of the five areas of need were selected from both institutions and charged with the development of problem statements, research questions, and project scope; the definition of expected research outcomes; and the identification of research area interfaces.

The action plan identifies six interconnected task-level activities that were executed to address open technical questions regarding the safe storage of ASNF (Step 2): ${ }^{6}$

- Task 1: (Oxy)hydroxide layer behavior and chemistry

- Task 2: Radiolytic gas generation

- Task 3: Sealed and vented system episodic breathing

- Task 4: Performance of ASNF in dry storage

- Task 5: Oxide layer response to drying

- Task 6: Surrogate sample preparation and validation experiment.

These six tasks share a common focus of assessing ASNF behavior in a long-term dry storage canister environment. The modeling and simulation (M\&S) work conducted under Task 3 interconnects with the empirical data and models developed in the other tasks and allows for the formation of a performance predicting tool. This tool can be used to compute important parameters such as the radiolytic gas generation of ASNF dry storage configurations for storage periods of 50 years and more.

To complete Step 3, an instrumented dry storage canister lid technology demonstration was considered as part of a full-scale dry storage technology readiness demonstration at INL. The technology development and selection for monitoring the ASNF dry storage in vented CPP-603 canisters and sealed DOE Standard Canisters ${ }^{\mathrm{a}}$ is currently ongoing. Possible next steps in this process include the implementation of the selected technology into an integrated lid system, followed by the fabrication and extensive testing of lid prototypes.

The remaining technical information gaps that are of importance to the dry storage of ASNF and of DOE-owned SNF in general (e.g., revisiting the structural capacity of the DOE Standard Canister) are being addressed by the EMTD project via several separate activities. ${ }^{5}$ All work completed to close these technology and knowledge gaps support the conclusion that extended ASNF dry storage is both safe and viable.

a The dry storage of ASNF was successfully implemented at the DOE complex at the Hanford site (i.e., loading aluminumclad, uranium-core single-pass reactor fuel into the Multi-Canister Overpack canister) and in the Irradiated Fuel Storage Facility in Building CPP-603, located at the Idaho Nuclear Technology and Engineering Center (e.g., storing Advanced Test Reactor fuel). Establishing the technical basis - including the verification of successful drying processes and dry storage system capabilities for the extended dry storage of ASNF within the Idaho Nuclear Technology and Engineering Center's vented canisters and within sealed DOE Standard Canisters - are the goals of the EMTD project.

The DOE Standard Canister was developed in the late 1990s for long-term storage of a variety of DOE-owned SNF types, followed by transportation to a federal repository for ultimate co-disposal together with DOE high-level waste canisters in a waste package as part of the federal repository's engineered barrier system. ${ }^{7,8}$ 


\section{QUALITY ASSURANCE}

This report presents results and information generated under the INL Quality Assurance Program described in PDD-13000 and the SRNL Task Technical and Quality Assurance Plan SRNL-RP-201800610 (Reference 9,10). This includes the following NQA-1-2008/1a-2009 requirements, or equivalent requirements:

- Requirement 3: Design Control

- Requirement 4: Procurement Document Control (if purchasing items or services)

- Requirement 6: Document Control

- Requirement 7: Control of Purchased Items and Services (when items are used or purchased that are critical to the pedigree of results)

- Requirement 8: Identification and Control of Items (when items are used or purchased that are critical to the pedigree of results)

- Requirement 9: Control of Special Processes

- Requirement 10: Inspection

- Requirement 11: Test Control

- Requirement 12: Control of Measuring and Test Equipment

- Requirement 13: Handling, Storage, and Shipping (when items are used or purchased that are critical to the pedigree of results)

- Requirement 15: Nonconformance Reporting (for items/materials of know function or properties that are not conforming that could affect the pedigree of results)

- Requirement 16: Corrective Action (for items/materials of know function or properties that are not conforming that could affect the pedigree of results)

- Requirement 17: Quality Assurance Records

- Subpart 2.7: Quality Assurance Requirements for Computer Software for Nuclear Facility Applications.

\section{TECHNICAL BASIS FOR EXTENDED DRY STORAGE OF ASNF}

This report serves to present the technical basis to ensure safe, extended ASNF dry storage developed by conducting research activities within the scope of the EMTD project - along with the primary findings and conclusions resulting from this work. The following sections provide a summary on how each of the five technical gaps identified by the SNFWG was addressed and closed, and points the reader to corresponding project reports that provide in-depth descriptions on the executed research activities and associated results and findings.

\subsection{Behavior and Chemistry of (Oxy)hydroxide Layers for the Range of ASNF Designs and Dry Storage Configurations.}

(Oxy)hydroxides are a distinguishing feature of ASNF and could form on the cladding of the fuel by virtue of thermal and radiolytic corrosion during both reactor operations and post-discharge wet and/or dry storage. The first technical information gap identified by the SNFWG centers around the corrosion behavior and chemistry of these (oxy)hydroxide layers during dry storage. Key activities of the conducted 
research to address this gap include detailed characterizations of the (oxy)hydroxide films from: (1) Advanced Test Reactor (ATR) ASNF featuring wet and dry storage histories at INL and (2) several other ASNF types that feature wet storage histories and were collected from the Savannah River Site L Basin inventory. Other activities include experimental work on surrogate ASNF material. The key findings of the conducted work to close the associated technical gap are:

- The conducted experiments show that radiation could accelerate the corrosion of pristine aluminum alloys when present in liquid water at room temperature, developing a diverse composition of multilayered oxides. ${ }^{11}$

- The testing of aluminum samples under carefully controlled temperature and humidity exposure conditions to quantify oxide film growth and $\mathrm{H}_{2}$ release indicate that the attendant (existing) (oxy)hydroxide layers on ASNF will prevent a significant additional corrosion layer growth under the bounding conditions of expected dry storage. ${ }^{12,13}$

- Examination of (oxy)hydroxide layers on wet- and dry-stored ASNF point to a nominal peak (oxy)hydroxide layer thickness of $15 \mu \mathrm{m}$, with possible localized thicker layers or oxide blooms. ${ }^{14,15,16}$

- Surrogate ASNF specimens can effectively simulate the types and morphologies of actual ASNF materials, including pre-filming characteristics. ${ }^{17,18}$

- The (oxy)hydroxide types found on ASNF include gibbsite, bayerite, and boehmite. ${ }^{14,15}$

- $\mathrm{No}_{2}$ is expected to be generated due to the corrosion of attendant (existing) (oxy)hydroxide layers in the range of temperatures anticipated during dry storage. ${ }^{19}$

All work completed to close this knowledge gap supports the conclusion that extended ASNF dry storage is both safe and viable.

\subsection{Resolution of Radiolytic Gas Generation Data for ASNF (Oxy)hydroxide Layers.}

Other EMTD-funded activities focused on generating data on the radiolytic behavior of ASNF. The radiolytic gas generation of $\mathrm{H}_{2}$ - a phenomenon that poses a challenge to ASNF dry storage - occurs when hydrated oxides are exposed to gamma radiation. First-ever data on the radiolytic $\mathrm{H}_{2}$ yield from (oxy)hydroxides on aluminum alloys were generated, focusing on representative sample configurations, such as pre-corroded aluminum coupons or actual ASNF in helium (He) backfill atmospheres under radiation. The studies included investigations on the effects of high-dose (post-linear-trend) conditions, drying temperatures, and aluminum alloy type on radiolytic gas generation. The key findings of the conducted work to close the associated technical gap are:

- $\mathrm{H}_{2}$ generation can be directly attributed to the presence of corroded aluminum and adsorbed water, and the $\mathrm{H}_{2}$ yields are directly dependent on the absorbed gamma dose, relative humidity, and cover gas composition. ${ }^{20,21}$ Further, $\mathrm{H}_{2}$ generation increases with the increasing availability of corrosion products. A positive correlation between the (oxy)hydroxide surface area and $\mathrm{H}_{2}$ generation is suspected, although it could not be confirmed empirically. ${ }^{22}$

- Physisorbed water or water trapped in porous (oxy)hydroxide layers is suspected to be the main precursors of radiolytic $\mathrm{H}_{2}$ generation at low radiation doses, although in significantly corroded ASNF material, the contribution of chemisorbed water to $\mathrm{H}_{2}$ generation may be more significant. $^{22}$

- Experimentally collected $\mathrm{H}_{2}$ generation data can be used successfully to predict $\mathrm{H}_{2}$ generation in ASNF dry storage configurations. ${ }^{21}$ 
- The consequences (e.g., sealed canister pressure and canister atmosphere flammability) of radiolytic $\mathrm{H}_{2}$ generation from (oxy)hydroxide layers on dry-stored ASNF under gamma irradiation can be effectively simulated and evaluated using experimentally derived data, for dry storage periods of 50 years or more. This includes sealed and vented dry storage configurations of ATR and other ASNF types within canisters with different backfill gases, such as He. ${ }^{23,24,25,26,27,28,29}$

All work completed to close this knowledge gap supports the conclusion that extended ASNF dry storage is both safe and viable.

\subsection{Combined Effect of Episodic Breathing and Radiolytic Generation of Potentially Corrosive Gases in Sealed and Vented Systems.}

The newly generated data on radiolytic gas yields were input into 3D multiphysics computational fluid dynamics models. The models considered both sealed and vented ASNF dry storage canister configurations and demonstrated the ability to simulate transient conditions - allowing for conclusions on dry storage safety for periods of 50 years or more - and the effects of various dry storage conditions, such as ASNF type; thickness of (oxy)hydroxide layers; ASNF decay heat; amount of residual, physisorbed, and chemisorbed water in the canister or (oxy)hydroxide layer; or type of cover gas. The key findings of the conducted work to close the associated technical gap are the following:

- Numerical simulations under bounding assumptions predicted that large amounts (i.e., $\sim 16-$ 17 vol.\%) of $\mathrm{H}_{2}$ could be produced in sealed DOE Standard Canisters fully loaded with ASNF over a 50-year dry storage duration. A strong dependency on ASNF decay heat assumptions can be observed. The analyzed dry storage configurations predicted that a canister fully loaded with ATR ASNF represents the bounding case with regard to $\mathrm{H}_{2}$ content, compared to simulations that include the University of Missouri Research Reactor (MURR) and Oak Ridge National Laboratory High Flux Isotope Reactor ASNF. ${ }^{29}$

- Numerical simulations under bounding assumptions predicted that only extremely small amounts (i.e., $\sim 5 \times 10^{-7}$ vol. \%) of molecular oxygen $\left(\mathrm{O}_{2}\right)$ could be produced in sealed DOE Standard Canisters fully loaded with ASNF over a 50 -year dry storage duration. ${ }^{29}$ Thus, canister atmosphere flammability can be eliminated as a safety concern when assuming that a minimum $\mathrm{O}_{2}$ content of $5 \mathrm{vol} . \%$ is needed to generate a flammable gas mix $^{\mathrm{b}}$.

- Numerical simulations under bounding assumptions predicted that the chemical specimen yield could increase the pressure to $2.6 \mathrm{~atm}$ over a 50 -year dry storage duration in sealed DOE Standard Canisters fully loaded with ASNF. A strong dependency on ASNF decay heat assumptions can be observed. The analyzed dry storage configurations predicted that a canister fully loaded with ATR ASNF represents a bounding configuration with regard to canister

\footnotetext{
b The flammability control strategy for in-canister ASNF is to credit an oxygen limit. Previous work on the Multi-Canister Overpack for DOE SNF at the Hanford site led to the engineering demonstration that a gas mix with less than 4 vol. $\%$ of oxygen can be considered non-flammable [CHPRC-01049, Rev. 0]. ${ }^{30}$ The U.S. Nuclear Regulatory Commission also recognizes $\mathrm{O}_{2}$ limits as a method of flammability control, suggesting a 5 vol.\% limit in the absence of an associated temperature criterion [Inspection Enforcement Information Notice No. 84-72]. ${ }^{31}$ In other words, flammability is only achievable given sufficient $\mathrm{H}_{2}$ and $\mathrm{O}_{2}$ in a gas composition. Thus, flammability control in ASNF dry storage can be met by limiting the $\mathrm{O}_{2}$ content in the gas mix to less than 5 mole percent. The following equation can be used to compute the oxygen content:
}

$$
\frac{n_{\text {oxygen }}}{n_{\text {oxygen }}+n_{\text {hydrogen }}+n_{\text {helium }}}=0.05
$$

where $n$ denotes the moles of $\mathrm{O}_{2}, \mathrm{H}_{2}$, and $\mathrm{He}$ in a canister. Backfilling the system with an inert gas, such as He, is the most common approach to flammability control. 
pressurization, compared to simulations including MURR and High Flux Isotope Reactor ASNF.$^{29}$ Further, the effect of the chemically bound water on the pressurization of a DOE Standard Canister filled with ASNF was already analyzed in DOE/SNF/REP-104 (Reference 32): The maximum amount of $\mathrm{H}_{2}$ that could be theoretically released from a (oxy)hydroxide layer is the same molecular content as the moles of hydrogen in the available water itself. For a canister loaded with fuel featuring an estimated bounding hydrated-oxide thickness of $34 \mu \mathrm{m}$, the maximum canister pressure was determined to be $22.7 \mathrm{~atm}$ at $315^{\circ} \mathrm{C}$. This well below the structural integrity limit of the DOE Standard Canister of approximately $34 \mathrm{~atm} .{ }^{34}$

- Numerical simulations under bounding assumptions predicted that negligible amounts (i.e., $\sim 0.002$ vol. $\%$ ) of $\mathrm{H}_{2}$ could be produced in vented dry storage canisters fully loaded with ASNF over a 50-year dry storage duration. Thus, canister atmosphere flammability can be eliminated as a safety concern when assuming that a minimum $\mathrm{H}_{2}$ content of 4 vol. $\%$ is needed to generate a flammable gas mix. ${ }^{33}$

- The low yield of nitric acid in the simulations of sealed and vented dry storage canister configurations show that neither radiolytic gas generation nor gas generation from thermal decomposition raises canister corrosion concerns during extended ASNF dry storage..$^{23,29}$

- Additional numerical simulations considering an increased corrosion rate of the borated stainlesssteel base material of ASNF baskets - caused by exposure to a strong radiation field - indicate the potential of reaching a $\mathrm{H}_{2}$ concentration of up to $\sim 73 \%$ and a DOE Standard Canister pressure of up to $5 \mathrm{~atm}$. This case requires the presence of enough residual water/water vapor to proceed, with negligible corrosion expected if the fuel and air in the canister are sufficiently dried. The limited inventory of $\mathrm{O}_{2}$ in these simulations prevents the build-up of a flammable canister atmosphere, and the pressure remains well below the structural integrity of a DOE Standard Canister. ${ }^{34,35}$

- The numerical simulations completed as of today considered ASNF dry storage durations limited to durations of up to 50 years. However, the decreasing slope of the trends in the time histories of nitric acid, $\mathrm{H}_{2}$, and $\mathrm{O}_{2}$ generation shown in Reference 23 (vented dry storage) and pressure, shown in Reference 29 (sealed dry storage), point to dry storage being safe for durations significantly longer than (i.e., multiples of) 50 years. Further, simulation results that include lowthermal output ASNF configurations could be representative for the expected chemical species yield of actual ASNF currently in vented dry storage (some of which has been stored for decades) during the next 50 years, supporting the conclusion that extended (more than 50 years) dry storage is safe. Furthermore, the validation of trends identified in available simulation results is anticipated by expanding (as part of currently ongoing activities) these simulations to storage periods beyond 50 years.

All work completed to close this knowledge gap supports the conclusion that extended ASNF dry storage is both safe and viable.

\subsection{Performance of Research Test Reactor ASNF in Existing Dry Storage Systems.}

To understand the performance of ASNF dry storage configurations, examinations and characterizations of currently wet- and dry-stored ASNF were conducted. This included the identification and characterization of changes in the (oxy)hydroxide layers, as well as changes in the ASNF material itself - such as ATR, MURR, and other research reactors - that might have occurred during storage. The key findings of the conducted work to close the associated technical gap are:

- No significant changes were observed in the characteristics of (oxy)hydroxide films located on ATR ASNF as a result of undergoing irradiation in the ATR or placement in either wet or dry 
storage for periods of up to 22 years. This indicates that limited change will occur in ATR ASNF as a result of irradiation, wet storage, and subsequent extended dry storage. ${ }^{36}$

- However, the characterization of other ASNF types (i.e., from Uruguay Reactor, MURR, and Savannah River Site Production Reactors) indicates that post-operational oxide growth during wet storage is possible, particularly for fuel types operated at higher temperatures. ${ }^{14}$

- Remarkable corrosion product features occasionally found are puffy white oxide blooms localized on some ATR ASNF plates, likely introduced during ASNF handling - by an abrasion of the protective boehmite layer which is generated in the ATR fuel manufacturing process. Nevertheless, these blooms appeared to have remained stable during an ASNF dry storage period of 22 years. ${ }^{36}$

- Instrumentation technology was developed and successfully tested that could be used for continuous performance monitoring of ASNF dry storage configurations in existing CPP-603 dry storage canisters and DOE Standard Canisters of extended periods of time. If collected, the data could be used to further validate and verify the key findings of the ASNF dry storage-related EMTD project activities. ${ }^{37,38}$

All work completed to close this knowledge gap supports the conclusion that extended ASNF dry storage is both safe and viable.

\subsection{Effects of High-Temperature (i.e., Greater than $100^{\circ} \mathrm{C}$ ) Drying on the Chemistry and Behavior of (Oxy)hydroxide Layers.}

Research was completed to understand how SNF drying protocols, such as vacuum drying or forced helium dehydration (FHD), could be used to prepare ASNF for extended dry storage in sealed and vented canister systems. The focus of these investigations was put on measuring post-drying residual moisture quantities in the form of free water in the canister, and physisorbed and chemisorbed water in the (oxy)hydroxide layers. Further, associated drying protocol conditions, such as the drying temperature and duration and their effects on the characteristics of ASNF (oxy)hydroxide layers, were evaluated. The activities included small-scale laboratory experiments on individual aluminum alloy and ASNF samples, and a large-scale drying test campaign using mock full-scale ATR-design assemblies, which carried surrogate, pre-corroded fuel plates and were loaded into a DOE Standard Canister mock-up. The key findings of the conducted work to close the associated technical gap are:

- Thermal drying can lead to a significant reduction in radiolytic $\mathrm{H}_{2}$ generation. ${ }^{22}$

- Removal of residual or physisorbed water from ASNF dry storage configurations is achievable with commonly used processes such as vacuum drying or FHD. ${ }^{39}$ There are indications that under specific drying conditions and processes, part of the chemisorbed water could be removed from the (oxy)hydroxide layers as well. ${ }^{22}$ Compared to vacuum drying, FHD demonstrated a better performance in partly removing chemisorbed water and in achieving uniform ASNF cladding temperatures. ${ }^{39}$

- Only a weak relationship between drying duration and mass loss can be observed during the thermogravimetric analysis of pre-corroded aluminum samples. Further, FHD and vacuum drying experiments using various thermal conditions demonstrated the removal of most bulk water within 3 hours and 4 hours, respectively, of the drying process initiation. However, an increase in drying temperature can reduce the time needed to complete an ASNF FHD process. ${ }^{39}$

- Even without removing any of the chemically bound water in a DOE Standard Canister loaded with ASNF, the canister pressurization is expected to remain well within the structural capacity of the canister during extended storage (i.e., $<34 \mathrm{~atm}$ ). ${ }^{29,34}$ 
- For all test temperature conditions, water mass loss from (oxy)hydroxide substrates on ASNF and pre-corroded aluminum samples demonstrated a positive correlation with an increasing drying temperature, although most mass change occurred between 200 and $300^{\circ} \mathrm{C} .{ }^{16,19}$

- Dehydration of pre-corroded aluminum samples due to the loss of physisorbed and/or chemisorbed water can take place at temperatures as low as $180^{\circ} \mathrm{C} .{ }^{19}$ Significant (although incomplete) dehydration of the tri-hydrated bayerite film could be practically achieved for ASNF by drying at temperatures slightly above $200^{\circ} \mathrm{C} .{ }^{39}$

- Phase changes in the (oxy)hydroxide layer were observed during drying at $\sim 220^{\circ} \mathrm{C}$. There are suspicions that these phase changes could be accompanied by the significant removal of chemisorbed water. ${ }^{39}$

- Changes in the aluminum-clad meat microstructures and material properties could take place at temperatures below $200^{\circ} \mathrm{C}$. These changes may be undesirable due to their potential of challenging the integrity of the fuel structure, but preventing these effects by limiting the drying temperature may be of competing interest in the selection of optimal thermal conditions for drying. ${ }^{40}$ However, some aluminum-clad fuels may have experienced associated changes during in-reactor service already, when reaching peak operating temperatures.

All work completed to close this knowledge gap supports the conclusion that extended ASNF dry storage is both safe and viable.

\section{CONCLUSIONS}

This report addresses previously identified technical knowledge and technology gaps and presents the key findings of the multiyear, EMTD-funded research efforts with the goal of evaluating whether ASNF can be safely stored dry for many decades and whether changes to existing ASNF management practices are appropriate. The findings formulate the technical basis for the extended dry storage of ASNF, leading to the main conclusion:

All completed work to close the identified knowledge gaps on extended (>50 years) ASNF dry storage supports the conclusion that extended ASNF dry storage is both safe and viable.

More specifically, the following conclusions can be drawn pertaining to the safety and viability of (1) extended, vented dry storage, (2) extended, sealed dry storage, and (3) technological approaches to monitor vented and sealed ASNF dry storage configurations:

1. Extended, vented dry storage of ASNF is both safe and viable. The radiolytic gas generation testing, characterization of actual ASNF sampled from wet and dry storage, drying technology evaluations, as well as the M\&S of the ASNF performance in its current dry storage configurations show that ASNF presently contained in vented dry storage canisters can remain safely stored for extended dry storage periods in their current configurations pending ultimate disposition. That is, the yield of chemical species, such as nitric acid, $\mathrm{H}_{2}$, and $\mathrm{O}_{2}$, do not raise any canister corrosion or flammability concerns.

2. Extended, sealed dry storage of ASNF is both safe and viable. The radiolytic gas generation testing, characterization of actual ASNF sampled from wet and dry storage, drying technology evaluations, as well as the M\&S of ASNF performance in potential future dry storage configurations show that ASNF can be safely placed in sealed dry storage canister for extended periods of time without causing corrosion degradation, canister pressurization, or canister flammability challenges, pending ultimate disposition. That is, the yield of chemical species, such as nitric acid, $\mathrm{H}_{2}$, and $\mathrm{O}_{2}$, do not raise any canister corrosion, overpressurization, or flammability concerns. 
3. Monitoring of extended dry storage of ASNF is technically viable. Reliable technology to monitor the performance of ASNF in vented and sealed dry storage systems was identified and prototypic instrumentation systems were developed. These systems could be utilized to further validate and verify the key findings of the conducted evaluations, providing additional assurance of safe and effective ASNF dry storage until final disposition.

\section{REFERENCES}

1. Idaho National Laboratory, 2021. "The Department of Energy Spent Fuel Database (SFD)." Version 8.0.7, June 9, 2021.

2. Lacroix, L. L., et al. 2017. "Aluminum-Clad Spent Nuclear Fuel: Technical Considerations and Challenges for Extended ( $>50$ Years) Dry Storage.” DOE-ID/RPT-1575, U. S. Department of Energy-Idaho.

3. Eidelpes, E. and R. Sindelar. 2021. "Technology Development for Aluminum-clad Spent Nuclear Fuel for Extended Dry Storage-Status Report-Fiscal Year 2021.” INL/EXT-21-64476, Idaho National Laboratory.

4. Connolly, M. and J. Jarrell. 2018. “Aluminum Clad Spent Nuclear Fuel Long Term Dry Storage Technical Issues Project Execution Plan.” PLN-5596, Idaho National Laboratory.

5. Jarrell, J. and Eidelpes, E. 2021. "Environmental Management Spent Nuclear Fuel Technology Development Project Execution Plan.” PLN-6658, Idaho National Laboratory.

6. Connolly, M. and J. Jarrell. 2017. “Aluminum Clad Spent Nuclear Fuel Long Term Dry Storage Technical Issues Action Plan-Technical and Engineering Activities." INL/EXT-17-43908, Idaho National Laboratory. https://doi.org/10.2172/1466830.

7. U. S. Department of Energy. 1999. "Preliminary Design Specification for Department of Energy Standardized Spent Nuclear Fuel Canisters: Volume I-Design Specifications/Volume II-Rationale Document.” DOE/SNF/REP-011, Volume I and II, Revision 3, August 17, 1999. https://doi.org/10.2172/665971.

8. ISF-ME-S-16000. 2002. “18” O. D. SNF Canister Fabrication (Short Canisters).” Revision 4, Sheets 1 to 6, Idaho Spent Fuel Project, Foster Wheeler Environmental Corporation, Idaho Falls, Idaho.

9. PDD-13000. 2018. “Quality Assurance Program Description.” Revision 8, Idaho National Laboratory.

10. Metzger, K. E. 2018. "Task Technical and Quality Assurance Plan for Aluminum Clad SNF Dry Storage Studies.” SRNL-RP-2018-00610, Savannah River National Laboratory.

11. Parker-Quaife, E. H. et al. 2019. "Radiation-induced Changes in Corrosion of AA1100." INL/EXT19-52738, Revision 1, Idaho National Laboratory.

12. Lister, T. E. 2018. "Vapor Phase Corrosion Testing of Pretreated AA1100." INL/EXT-18-52249, Idaho National Laboratory.

13. Lister, T. E. and C. J. Orme. 2019. "Vapor Phase Corrosion Testing of Pretreated AA6061 and AA5052.” INL/EXT-19-53964, Idaho National Laboratory.

14. Olson, L. et al. 2019. "Characterization of Oxide Films on Aluminum Materials following Reactor exposure and Wet Storage in the SRS L-Basin." SRNL-STI-2019-00058, Revision 0, Savannah River National Laboratory. https://doi.org/10.2172/1501352. 
15. Olson, L. et al. 2018. "Characterization of Oxyhydroxides on a Dry-Stored Fuel Plate from L-Basin." SRNL-STI-2018-00428, Revision 0, Savannah River National Laboratory.

16. Winston, P. et al. 2018. "Aluminum Spent Nuclear Fuel Performance in Dry Storage - Task 4 Objective 1 Initial Characterization of ATR End Box Samples.” INL/EXT-18-51230, Idaho National Laboratory.

17. d'Entremont, A. L. et al. 2018. "Preparation of Aluminum Oxide Films under Water Exposure Preliminary Report on 6061 Series Alloys." SRNL-STI-2018-00449, Revision 0, Savannah River National Laboratory.

18. d'Entremont, A. L. et al. 2018. "Preparation of Aluminum Oxide Films under Water Exposure Preliminary Report on 5052 Series Alloys." SRNL-STI-2018-00646, Revision 0, Savannah River National Laboratory, Jackson, South Carolina. https://doi.org/10.2172/1485265.

19. Lister, T. E. and C. J. Orme. 2020. "Vapor Phase Corrosion of Pretreated Aluminum Alloys: Final Report.” INL/EXT-19-56497, Revision. 1, Idaho National Laboratory.

20. Parker-Quaife, E. H. et al. 2020. "Radiation-induced Molecular Hydrogen Gas Generation by Precorroded Aluminum Ally 1100." Radiation Physics and Chemistry 177, (Winter): 109117. https://doi.org/10.1016/j.radphyschem.2020.109117.

21. Parker-Quaife, E. H. and G. P. Horne. 2021. "Preliminary Radiolytic Gas Generation Measurements from Helium-Backfilled Samples.” INL/EXT-21-61404, Revision 0, Idaho National Laboratory.

22. Verst, C. G., et al. 2021. "Measurement of Radiolytic Hydrogen Generation from Hydrated Aluminum Surfaces in a Gamma Irradiation Field.” SRNL-STI-2021-00386, Revision 0, Savannah River National Laboratory.

23. Abboud, A. and H. Huang. 2019. "Full-scale Model of Dry Storage of Aluminum Clad Spent Nuclear Fuel.” INL/EXT-19-55185, Revision 1, Idaho National Laboratory.

24. Abboud, A. 2020. "Modeling of SRS Aluminum-clad Spent Nuclear Fuel in Standard DOE Sealed Canisters.” INL/EXT-20-57893, Revision 0, Idaho National Laboratory. https://doi.org/10.2172/1644680.

25. Abboud, A. 2021. "Modeling of ATR Fuel in DOE Standard Canisters with Helium Backfilled Condition." INL/EXT-21-62306, Revision 0, Idaho National Laboratory.

26. Abboud, A and H. Huang. 2021. "Development of Transient Coupled Chemical-Thermal-Fluid Field Simulation for Sealed Aluminum-clad Spent Nuclear Fuel Storage Canister." INL/EXT-18-51683, Revision 1, Idaho National Laboratory.

27. Abboud, A and H. Huang. 2018. "Development of Transient Coupled Chemical-Thermal-Fluid Multiphysics Simulation for Unsealed, Vented Aluminum-clad Spent Nuclear Fuel Storage Canister." INL/EXT-18-51681, Revision 1, Idaho National Laboratory.

28. Abboud, A. 2020. “Guide to CFD-Chemical Model for Spent Fuel Storage.” INL/EXT-20-58578 Revision 1, Idaho National Laboratory.

29. Abboud, A. 2021. "Modeling Summary of ASNF in DOE Sealed Standard Canisters." INL/EXT-2164413 Revision 0, Idaho National Laboratory.

30. Bader, K. R. 2010. "MCO Internal Gas Composition and Pressure during Interim Storage at the Canister Storage Building." CHPRC-01049, Revision 0, DOE Hanford Site.

31. U.S. NRC. 1984. "Information Notice No. 84-72: Clarification of Conditions for Waste Shipments Subject to Hydrogen Gas Generation.” Washington, D.C. 
32. Wertsching. A. K. 2007. "Materials Interactions on Canister Integrity During Storage and Transport." DOE/SNF/REP-104, U. S. Department of Energy.

33. Zabetakis, M. G. 1965. "Flammability Characteristics of Combustible Gases and Vapors." Bureau of Mines, Washington DC.

34. ECAR-4632. 2019. "Supplemental Evaluation of the Idaho Spent Fuel Project Canister for Accidental Drops." Idaho National Laboratory.

35. Abboud, A. and S. Saha. 2020. "Chemical Modeling of ATR Fuel in DOE Standard Canisters with Borated Stainless Steel Corrosion.” INL/EXT-20-59994, Revision 0, Idaho National Laboratory.

36. Winston, P. et al. 2020. “Aluminum Spent Nuclear Fuel Performance in Dry Storage - Task 4 Aluminum Oxide Sampling of ATR Dry-Stored Fuel.” INL/EXT-20-58404, Revision 0, Idaho National Laboratory. https://doi.org/10.2172/1642905.

37. Herman, D. 2019. "Status Update on the Instrumented Lid Project." SRNL-L2240-2019-00007, Savannah River National Laboratory.

38. Fanning, R. M. and E. D. Kitcher. 2021. "Feasibility Studies into Development of a Remote CanisterMonitoring System.” INL/EXT-21-64564, Revision 0, Idaho National Laboratory.

39. Perry, J., et. al. 2021. “Engineering-Scale Drying of Aluminum Spent Nuclear Fuel.” INL/EXT-2162416, Idaho National Laboratory.

40. Glazoff, M. V., T. E. Lister, and R. E. Smith. 2020. "Transition of Spent Nuclear Fuel to Dry Storage - Modeling of Aluminum Spent Nuclear Fuel Cladding Alloy.” INL/EXT-18-51694, Revision 1, Idaho National Laboratory. 